\title{
Influence Mechanism of Organizational Flexibility on Enterprise Competitiveness: The Mediating Role of Organizational Innovation
}

\author{
Guodong Ni ${ }^{1,2, * \mathbb{D}}$, Heng Xu ${ }^{1}$, Qingbin Cui ${ }^{3}$, Yaning Qiao ${ }^{1,2}$, Ziyao Zhang ${ }^{1}$, Huaikun Li $^{1}$ and Paul J. Hickey ${ }^{3}$ \\ 1 School of Mechanics and Civil Engineering, China University of Mining and Technology, \\ Xuzhou 221116, China; TS18030227A31@cumt.edu.cn (H.X.); yaning.qiao@cumt.edu.cn (Y.Q.); \\ zhangziyao@cumt.edu.cn (Z.Z.); lihuaikun@cumt.edu.cn (H.L.) \\ 2 Research Center for Digitalized Construction and Knowledge Engineering, School of Mechanics and Civil \\ Engineering, China University of Mining and Technology, Xuzhou 221116, China \\ 3 Department of Civil and Environmental Engineering, A. James Clark School of Engineering, University of \\ Maryland, College Park, MD 20742, USA; cui@umd.edu (Q.C.); pauljhickey@verizon.net (P.J.H.) \\ * Correspondence: niguodong@cumt.edu.cn
}

Citation: Ni, G.; Xu, H.; Cui, Q.; Qiao,

Y.; Zhang, Z.; Li, H.; Hickey, P.J.

Influence Mechanism of

Organizational Flexibility on Enterprise Competitiveness: The Mediating Role of Organizational Innovation. Sustainability 2021, 13, 176. https://dx.doi.org/

10.3390/su13010176

Received: 8 November 2020 Accepted: 23 December 2020 Published: 27 December 2020

Publisher's Note: MDPI stays neutral with regard to jurisdictional claims in published maps and institutional affiliations.

Copyright: (C) 2020 by the authors. Licensee MDPI, Basel, Switzerland. This article is an open access article distributed under the terms and conditions of the Creative Commons Attribution (CC BY) license (https: / / creativecommons.org/ licenses/by/4.0/).
Abstract: Organizational success heavily relies on the competitiveness of products and services under rapidly changing market conditions. This enterprise competitiveness becomes more critical for project-based enterprises as modernization of the Chinese construction industry creates greater challenges and uncertainty in construction operations, which determines the sustainable advantages of enterprises to a certain degree. Traditional wisdom focuses on cost efficiency, asset differentiation, and service performance to gain competitive advantages. This paper explores the influence of organizational flexibility and organizational innovation on enterprise competitiveness for Chinese construction organizations. A designed structured questionnaire was developed and conducted targeting the project-based enterprises in China's construction industry and is accompanied by a structural equation modeling analysis. Results indicate a positive impact of organizational flexibility on enterprise competitiveness along with a mediation role of organizational innovation. The study concludes that new organizational strategies are required for Chinese project-based enterprises to maintain enterprise competitiveness in order to realize the sustainable development of enterprises.

Keywords: enterprise competitiveness; organizational flexibility; organizational innovation; modernization of construction industry; structural equation modeling

\section{Introduction}

In today's competitive business environment, how to enhance enterprise competitiveness has been a hot topic [1]. Existing studies show that strengthening leadership [2], establishing good relationships with partners [3], technological renovations [4], and capital investment [5] are all effective for the promotion of enterprise competitiveness. However, due to fast technological advancement, increased competition, market fluctuations [6], and even the impact of infectious diseases such as COVID-19, traditional measures are struggling to maintain competitiveness effectively for enterprises in turbulent and complex business environments. Flexibility plays an important role in keeping firms alive and prospering in changing market environments [7]. Thanks to flexibility, firms can react to environmental changes and uncertainties more quickly: They can absorb change, integrate, develop, and restructure resources and capabilities in the organization in a short time [8]. Besides, improving flexibility is considered a crucial tool that can predict organizational performance [9]. Therefore, enhancing flexibility serves as a feasible solution for promotion of enterprise competitiveness in a turbulent environment. Although there are sporadic clues to indicate that strengthening flexibility inside an organization is conducive to enterprise survival and development, to our knowledge, few empirical studies connect organizational 
flexibility with competitiveness, which turns out to be a barrier for further understanding of the competitiveness promotion mechanism under the flexibility perspective.

Generally, it takes a relatively long time to complete a construction project. The longer the project duration, the greater the risk and uncertainties, such as increases in the price of labor and material, payments delays, safety, quality, and poor estimating [10]. Long project duration brings more uncertainties and dynamic risks and makes it even more difficult to manage project results and profitability for Project-Based Enterprises (PBEs) in the construction industry, which generally includes construction, design, engineering management, real estate development, and consulting firms [11,12]. Thus, on the one hand, it is more difficult to remain flexible for construction industry PBEs compared with the manufacturing company. On the other hand, keeping flexibility would make more sense for construction industry PBEs. Once construction industry PBEs are more flexible, they can prevent risks and loss or seize the opportunity caused by uncertainty and changes in advance via rapid and active response, which can not only improve their profitability but also enable them to gain a stronger market competitive advantage.

For Chinese construction industry PBEs, the advantage of flexibility in facing uncertainties and promoting enterprise competitiveness is more prominent. Under the trend of deep integration into the global economy, with China's proposal of the "Belt and Road" initiative in 2013, the construction industry, as a supporting industry of the national economy in China [13], has accelerated the pace of undertaking projects overseas. Obviously, faced with the uncertainties and risks in overseas markets, continuous competitive improvement holds the key to survival and development of PBEs in China's construction industry $[14,15]$. The sustainable development of China's construction industry concerns not only the interests of China, but also the healthy development of the whole world economy. Meanwhile, the rapid development of construction industry standards demands PBEs constantly dealing with a large number of changes in the operating environment [16]. Contributing factors include fluctuating construction demands [16], changing procurement trends [17], clients' higher performance standards for building services [10], and higher technical requirements [16]. The combined effect of these changes forces firms to improve their viability and competitiveness in the business environment [7]. Similar situations are particularly prominent in China's construction industry. Since the strategy of Modernization of Construction Industry (MCI) was first proposed by Chinese authorities in 2013, governments have focused on deepening the construction industry reform. MCI refers to the transformation and upgrade of the construction industry, taking technological innovation as a guide, modern management as support, informatization as the means, and new construction industrialization as the core, the strategy aims to renew, transform, and upgrad the whole industrial chain of construction, thus realizing the transformation from the traditional production mode to the modern industrial production mode and improving the quality, efficiency, and benefits comprehensively. MCI is the key to realizing sustainable development and upgrading the construction industry. $\mathrm{MCI}$ involves many aspects, such as prefabricated building [18], construction industry informatization and industrialization [19], design and construction integration, green development concept, and sustainable strategy $[15,20,21]$. Current development trends in construction can fundamentally change the traditional production modes of the Chinese industry but also create many uncertainties and challenges to PBEs. Therefore, maintaining the advantage in competition and avoid elimination in continuously changing and uncertain market environments emerges as an urgent issue for PBEs leaders and managers in China's construction industry.

As is well-known, innovation might be one of a few lasting sources of enterprise competitive advantage $[22,23]$. Promoting organizational innovation (OI) actively within the enterprise aids in coping with environmental changes and uncertainties. Organizational innovation means that an organization adopts a new idea or behavior [24], which generally includes technological environment advancements and management modernization of the organization [25]. Implementing organizational innovation activities is conducive to increase productivity and profitability as well as to expand existing market shares and 
exploiting new markets [26]. Organizational innovation capacity is of vital importance in shaping PBEs competitiveness in the construction industry [15]. Meanwhile, there is evidence indicating that innovation partially mediates the relationship between organizational flexibility and project portfolio performance [9]. PBEs with flexibility are likely to use various organizational resources to fully realize the benefits of technological innovation and management innovation. Therefore, organizational innovation, together with organizational flexibility, will play a critical role in enhancing the PBEs' competitiveness in the current complex situation.

However, it remains unclear whether enterprise competitiveness can be promoted effectively by organizational flexibility in China's construction industry and whether organizational innovation can play a mediating role between organizational flexibility and enterprise competitiveness. Therefore, this paper tries to figure out these two questions and aims to explore the mechanism for improving enterprise competitiveness in China's construction industry with a specific focus on organizational flexibility and organizational innovation. On the basis of theoretical analysis, this study will set up a theoretical model of the influence mechanism of organizational flexibility on the enterprise competitiveness of PBEs through putting forward the research hypotheses. Then, based on China's construction industry under the background of $\mathrm{MCI}$, it will test the theoretical model and research hypotheses using the standard paradigm of empirical research, clarify the influence mechanism of organizational flexibility on enterprise competitiveness, and further verify the mediating role of organizational innovation.

\section{Theoretical Background}

\subsection{Enterprise Competitiveness}

Competitiveness can be regarded as an independent, dependent, or intermediary variable, depending on the perspective one takes in dealing with the problem. In the construction industry, the analysis of competitiveness is based on four levels: country, industry, firm, and project [2]. Among them, the firm's competitiveness provides the greatest interest for practitioners and attracts the most attention of researchers [27]. Many researchers emphasize the importance of competitiveness at the firm level $[21,28]$. Enterprise competitiveness for a coal firm, for example, refers to the enterprise's advantages compared with competitors in design, production, sale of products, personnel, technology, and management, considering price and non-price factors [29]. But for contractors, the firm's competitive advantage comes from its competitive strategy when facing strengths, weaknesses, opportunities, and threats, as well as its unique, irreplaceable, and inimitable resources [30]. The understandings of enterprise competitiveness are not the same in view of the differences between industry and research perspectives. It is necessary to clarify the connotation of the PBEs' competitiveness in the context of MCI.

Prior researchers tended to focus on how to measure and improve competitiveness [14,31]. According to [27], assets and processes within an organization (the measurement of competitive advantage) can be either tangible or intangible, including brand, reputation, culture, human resources, technology, market share, and profitability. In addition, Ghobadian et al. [32] proposed that identifying business opportunities such as increased market share, increased profitability, or reduced cost structure could lead to enterprise competitive advantage. In the construction sector, underlying contractor contributors can be divided into three parts: core competence, company strategy, and project performance [15]. According to [3], measurement indexes of enterprise competitiveness include firm image, financial ability, marketing ability, technical ability, management skill, and human resources advantage. Deng et al. [14] developed potential factors of the Chinese construction industry: domestic stable market, supply chain management, corporate management practices, qualified professionals, sound business climate, and migrant workers. These results indicate that the advantages in human resource, finance, market share, and management can form sources of enterprise competitiveness. In order to make the construction industry more competitive, Chinese PBEs need to not only learn from inter- 
national practices but also to adjust and complete them according to the Chinese market environment [33]. Under the background of MCI, new technologies and construction requirements bring great uncertainty to project investment and construction. Strengthening the project management ability of construction engineering enterprises is crucial to ensuring the output of high-quality products and services and the stable operation and decision-making efficiency of project teams. Building on the literature review and the PBEs characteristic of the construction industry, this study establishes the measurement structure of enterprise competitiveness about PBEs from the following five competitive advantages: Talent Competition Advantage (TCA), Financial Operation Advantage (FOA), Market Share Advantage (MSA), Enterprise Management Advantage (EMA), and Project Management Advantage (PMA), which will be tested by empirical research later. In this study, enterprise competitiveness is defined as providing products or services more effectively than other competitors, with the help of the advantages in talents, financial operation, market, organizational management, and project management, so as to gain profits and sustainable development.

\subsection{Organizational Flexibility}

Usually, flexibility is considered as an independent variable to predict the effectiveness of an organization [34] and refers to the degree to organizational capability to make positive changes and adapt to environmental disturbances [35]. What is similar to flexibility is the concept of agility, which appears later than flexibility [36]. Some researchers regard flexibility as the center of agility [37], other studies see agility as an extension of flexibility [38]. To eliminate this confusion, Abdelilah et al. [36] analyzed the development of flexibility and agility and their relationship. The study pointed out that flexibility is just a part of agility, and other types of flexibility can also be viewed as agility sub-capabilities or as agility enablers. Flexibility is considered an operational ability, while agility is a strategic ability that enables a firm to build a long-term strategic vision [36]. However, the above findings are only discussed in manufacturing and the supply chain. It is still urgent to figure out the connotation of flexibility in the construction industry.

Firms' potential primarily rests with intrinsic flexibility of its resources and its ability to coordinate the use of those resources to achieve strategic goals [39], and more importantly, firms can generate sustainable competitive advantages by effectively controlling and using their unique, irreplaceable, and inimitable resource [40]. Theoretically, situation awareness, management of key vulnerabilities, and adaptive ability are the main three attributes of organizational flexibility and associated performance improvement processes [41]. Flexibility management is vital for firms to survive in turbulent market environments [42]. Organizational attributes such as human resources [43], organizational learning [44], organizational structure and management style [45], technologies capabilities [46,47], and supply chain capabilities [48] may affect the firm's organizational flexibility. In the field of engineering construction, this topic attracted the attention of scholars, although research works are relatively few compared with other fields [6,7,49-51]. Organizational flexibility in construction can be defined as an ability for organization to make use of resources effectively to respond and adapt to environmental changes via continuous learning in a timely and reversible manner [7].

Prior research offers a multitude of approaches on the structural dimensions of organizational flexibility. Ozer [43] pointed out some critical elements of flexibility: human resources, operations, market, finance, technology, and management. According to Maghool [35], organizational flexibility can be divided into four dimensions: operational flexibility, financial flexibility, structural flexibility, and technological flexibility. Lim et al. [7] deemed that the definition of organizational flexibility for construction firms includes various dimensions. It can be interpreted as "operational", "tactical", or "strategic" flexibility. Other studies involved product development flexibility [52], supply chain flexibility [53], human resource flexibility [54], process flexibility [47,55], leadership flexibility [56,57], team flexibility [58], cross-cultural flexibility [59], and contractual flexibility [60]. 
However, specific structural dimensions of organizational flexibility need to be adjusted to match specific enterprise or organization type.

For PBEs in the construction industry, organizational structure, resource, leadership, and technological flexibility can be intuitively considered as necessary elements. Furthermore, corporate culture is a strategic asset [59], and ideal organizational culture builds a learning organization that encourages and fosters organizational growth [44]. Study results show cultural change relates closely to incremental and radical innovation [61]. Hence, cultural flexibility encourages individuals and organizations to learn and innovate, generating an open atmosphere in PBEs. Besides, the ability to innovate is a component of flexibility capabilities [62]. Considering the significance of organizational climate in construction innovation [63], the authors conclude that innovation flexibility is one of the most important dimensions for PBEs' organizational flexibility under the changeable construction market environment, which is verified in this study. In summary, organizational flexibility measurement metrics for construction industry PBEs include six dimensions in this study: Structural Flexibility (SF), Resource Flexibility (RF), Leadership Flexibility (LF), Cultural Flexibility (CF), Technological Flexibility (TF), and Innovative Flexibility (IF).

- Structural Flexibility-Ability of the organization to restructure [35].

- Resource Flexibility-Ability to transform resources into other beneficial uses, providing a buffer for organizations to adapt to changes in uncertain environments [64].

- Leadership Flexibility_Leadership's capability to play several different roles, sometimes even opposite roles, to meet the demand of rapid pace and diversity of activities in various contexts [57], and their ability to adapt to by adjusting goals with their own knowledge and ability.

- Cultural Flexibility-Ability to adjust corporate culture to form a mental model, sense of worth, and learning atmosphere in order to adapt to environmental changes and uncertainties effectively.

- Technological Flexibility-Ability to change technical capacity in line with the competitive requirements [35].

- Innovative Flexibility-Ability to develop new products or services to quickly adapt to market demands at low cost [65].

Measurement of organizational flexibility developed in this study will also be tested by future follow-up empirical research.

\subsection{Organizational Innovation}

For a long time, innovation has been considered as one of the critical factors to improve national economic growth, firms' competitiveness and living advantages [26,66-69]. The process of innovation generally includes three basic steps: starting with a preliminary idea, deciding to adopt the concept, and finally, implementing the innovation [24]. In the previous study, the development of new products and new technologies is regarded as an innovation, so innovation was initially considered as a technical term, a synonym for invention. However, the concept has expanded to cover many domains and features, especially in non-technological areas [70], among which management innovation deserves a place. Evan [25] theorized that both executive administrators and working level employees initiate improvements, depending upon the type of proposed change. Organizations can adopt inspiration originating from both ends of the organizational hierarchy: Management Innovation (MI) originates near the top of the hierarchy and trickles down while Technological Innovation (TI) emerges near the bottom of the hierarchy and trickles up [25]. Technological innovation is the act of turning an idea for a new product, process or service into a reality [25]; management innovation, on the other hand, is usually recognized as the adoption of new management practices, processes, rules, methods, and structures with the aim of achieving organizational goals [71,72] and benefitting long-term performance promotion [70]. The interest in management innovation has been growing recently [73-75].

In the construction industry, innovation is shaped by project demands and forced by various environmental factors and is regarded as a means of performance improvement $[66,76]$. 
Adopting new methods presents challenges because of the disjointed and project-based characteristics of construction projects [77]. Therefore, various practices are applied to promote innovation within an organization. Liu and Chan [78] verified the crucial role of learning transfer climate in promoting innovation in construction. Lijauco et al. [79] tested the potential relationships between cultural factors and tendencies for adopting new concepts in small to medium enterprises of the construction industry. The results show that corporate relationships, market orientation, and workforce capacity are the main factors. Ozorhon et al. [77] conducted a case study and reported that denying changes, insufficient experience, and lack of innovative products can restrict adoption. Based on the characteristics of construction organizations, components of organizational innovation capacity include entrepreneurship, culture, learning organization, human resources, and information management [15]. Using Thailand's Bang Na Expressway case study, Brockmann et al. [80] summed up the categories of innovation as product or construction technology within technical, management, or legal organizations. Meng and Brown [81] argued that innovation strategies in construction firms fall into four categories: technology, management, resource, and marketing. $\mathrm{MCI}$ brings the motive power for PBEs to search for new innovative sources in China, and these firms should carefully consider organizational innovation. In this paper, organizational innovation refers to integration and utilization of new products and services in technology or management, change of existing production methods, renewal of new management policies, or the implementation of new management systems [82]. Considering the equally important role of technology and management in the construction industry, this research constructed measurements of organizational innovation structures as two dimensions according to Evan [25]: technological innovation and organizational innovation, which will also be tested in follow-on investigations.

\section{Research Hypotheses and Theoretical Model}

\subsection{Organizational Flexibility and Enterprise Competitiveness}

Through continuous learning, a flexible firm can maintain its competitiveness [83] because organizational flexibility serves as the most important source of competitive advantage for firms in today's dynamic environment [7]. Flexibility has usually been recognized as an ability for individuals, communities, or organizations to deal with, adapt to, and recover from a disaster event [84]. An organization with heightened flexibility weathers both daily business problems and successfully navigates crisis situations, gaining advantages in the fierce market competition [41]. Organizational flexibility can improve a firm's maneuvering capacity, and it is also beneficial to adapt existing systems and processes to environmental changes [7]. Project management practices that focus on flexibility based on collaboration, exploratory learning, and adaptation improve time performance in complex infrastructure projects [51]. Changes resulting from MCI in China induced a complex process of responses. Demands for effective organizational structure, rapid technological advancement, recruitment of new talents, and management mode innovation place significant challenges on industry PBEs. Organizational flexibility should also be required to improve enterprise competitiveness and response to these challenges for PBEs, so as to remain viable in the business environment. Therefore, this study submits the following hypothesis:

Hypothesis 1 (H1). Organizational flexibility has a significant positive impact on enterprise competitiveness in the construction industry.

\subsection{Organizational Flexibility and Organizational Innovation}

Organizational nimbleness generates creative thought according to Vickery et al. [53], allowing the firm to develop new products or services and adapt to market demands quickly at low cost. Flexibility offers a solution to environmental uncertainty as members can adjust the project to possible consequences brought by uncertain circumstances [50]. The six dimensions of the flexibility construct established in this paper are closely con- 
nected with organizational innovation. Effective leadership encourages creativity in individual project teams across the construction sector [63,77], and leadership fosters ingenuity throughout organizations [85]. The strongest driving forces of change are technical problems in construction projects, client demands, and top management [86]. Establishing an open, productive culture improves relationships between company leadership and outside firms [63]. Cultural factors drive propensity for positive change within enterprises in the construction sector [79]. The contribution of tactical business strategies to innovation performance has been confirmed by firms in the Australian construction industry [87]; furthermore, the positive relationship between external human resource flexibility and innovation has also been tested [54]. Within the context of MCI in China, organizational flexibility will be conducive to taking advantage of all kinds of PBEs organizational resources to fully realize the benefits of technological innovation and management innovation. Thus, the hypotheses are put forward:

Hypothesis 2 (H2). Organizational flexibility has a significant positive impact on technological innovation in the construction industry.

Hypothesis 3 (H3). Organizational flexibility has a significant positive impact on management innovation in the construction industry.

\subsection{Organizational Innovation and Enterprise Competitiveness}

Innovation serves as an organizational key performance indicator; resourcefulness enhances productivity and financial outcomes, and competitiveness has an essential role in the construction sector in enhancing work effectiveness, efficiency, and business performance [63]. According to Ozorhon et al. [76], innovation can bring many benefits, such as increased productivity and client satisfaction at the project level, improved corporate image, enhanced technical and management capability, and experience acquired at the firm-level. The relationship between innovation and competition is the focus of many academic studies concerned with economic growth and development, and companies need innovative skills in creating, producing, marketing, and managing to gain competitive advantage in global markets [26]. With accelerating fluctuations in market economies, firms must pursue revolutionary changes to gain and maintain competitive advantage [22]. Development and sustainability of competitiveness are based on speed and efficiency of the implementation of innovations to some extent [4]. Whether based on passive or active responses, organizational innovation evolves into an important factor impacting enterprise competitiveness and determines organizational viability [88], which can be harvested through building firms' capacity [15]. Both management innovation and technological innovation contribute to organization performance positively [89]. Economists have widely recognized technological innovation as a source of economic growth [90]. Existing research shows the significant positive effect of green technological innovation ability on enterprise competitiveness [91], and technological innovation can increase the economic benefits of construction firms [92]. The significant role of management innovation in boosting enterprise performance and competitive advantage has been verified [74]. Thus, it can be concluded that technological innovation and management innovation are helpful in promoting the formation of enterprise competitiveness in the construction industry. Therefore, the following hypotheses are proposed:

Hypothesis $4 \mathbf{( H 4 ) . ~ T e c h n o l o g i c a l ~ i n n o v a t i o n ~ h a s ~ a ~ s i g n i f i c a n t ~ p o s i t i v e ~ i m p a c t ~ o n ~ e n t e r p r i s e ~}$ competitiveness in the construction industry.

Hypothesis 5 (H5). Management innovation has a significant positive impact on enterprise competitiveness in the construction industry. 


\subsection{Technological Innovation and Management Innovation}

Researchers approved and adopted the viewpoint of the double cores model in regards to organizational innovation (e.g., technological innovation and management innovation) [24]. The impact of technological innovation and management innovation on organizational performance has been tested [89], which indicates that technological innovation and management innovation have a combined impact on performance and that a close relationship develops between technological innovation and management innovation [93]. The literature review for this study identified limited existing studies exploring the direct relationship between technological innovation and management innovation. Against the background of MCI in China, PBEs should master many evolving technologies highlighted by prefabricated construction technology, Building Information Model (BIM) technology, Radio Frequency Identification (RFID), green construction technology, and sponge city construction technology. Technological revolution requires the support of management reform, which means that technological innovation is conducive to the development of management innovation and management innovation needs to be consistent with technological innovation. Therefore, the following hypothesis is proposed:

Hypothesis 6 (H6). Technological innovation has a significant positive impact on management innovation in the construction industry.

\subsection{Mediating Role of Technological Innovation and Management Innovation}

For business operations and industrial development, the institutional environment is an important external environment and can influence the performance of the enterprise. The existing study shows that institutional environment changes may have an effect on enterprise technology innovation motivation [94]. Flexibility offers a solution to environmental uncertainty as members can adjust the project to possible consequences brought by uncertain circumstances [50]. It means that enhancing flexibility is helpful for keeping technological innovation motivation. As proposed in this paper, technology flexibility, the main component of organizational flexibility, refers to firms' ability to change the technical capacity in line with the competitive requirements [35]. Technological adjustments according to market demands change are likely to lead to innovation, and technology innovation is usually viewed as an effective assessment indicator of competitiveness [91]. Therefore, surmising the mediator role of technological innovation is reasonable.

Although there is no direct evidence indicating the role of management innovation between organizational flexibility and enterprise competitiveness, previous studies provide useful information to sort out the underlying logic. Inspiration of management innovation is considered as originating from the top of the hierarchy [25] when it comes to non-technological areas, such as management practices, processes, rules, methods, and structures $[71,72]$. Leaders possessing flexibility would be more likely to play several different roles to meet the demand for rapid pace and diversity of activities in various contexts [57]. Besides, the adaption of organizational culture-such as common values, beliefs and attitudes, and work practices at the organizational and national levels-to management innovations has be viewed as important [95]. Companies with flexibility in culture can align with management innovation practices quickly, and management innovation is found to have a positive relationship with firms' overall performance and financial performance [96]. It is worth noting that a mediating role of management innovation between the effects of manufacturing flexibility on organizational performance has been tested by an empirical study of 159 Spanish firms [97].

Within the context of MCI in China, organizational flexibility offers a solution to environmental uncertainty. PBEs with flexibility can respond to market demands promptly by making active adjustments in culture, resources, structure, and technology [35], which provides driving force for innovation. The dynamic environment can effectively improve the learning ability of the organization and increase the probability of implementing innovative activities. Technology innovation has been always recognized as an important 
approach to gain competitive advantage [90]. However, the adoption of new technology poses a higher challenge to the management ability of enterprises as the financial benefit of technology will be reduced without the support of management regulation, process, and method. Sometimes, technology innovation is an accelerator of the management revolution. For example, blockchain technology applied in prefabricated buildings can effectively stimulate innovation in quality management [98].

Based on the analysis above, three hypotheses are proposed:

Hypothesis $7 \mathbf{a}(\mathbf{H 7 a})$. Technological innovation mediates the relation between organizational flexibility and enterprise competitiveness in the construction industry.

Hypothesis $\mathbf{7 b} \mathbf{( H 7 b ) . ~ M a n a g e m e n t ~ i n n o v a t i o n ~ m e d i a t e s ~ t h e ~ r e l a t i o n ~ b e t w e e n ~ o r g a n i z a t i o n a l ~}$ flexibility and enterprise competitiveness in the construction industry.

Hypothesis $7 \mathrm{c}(\mathbf{H 7 c )}$. Technological innovation and management innovation serially mediate the relation between organizational flexibility and enterprise competitiveness in the construction industry.

Based on the above analysis and hypotheses, the theoretical model is established which is shown in Figure 1.

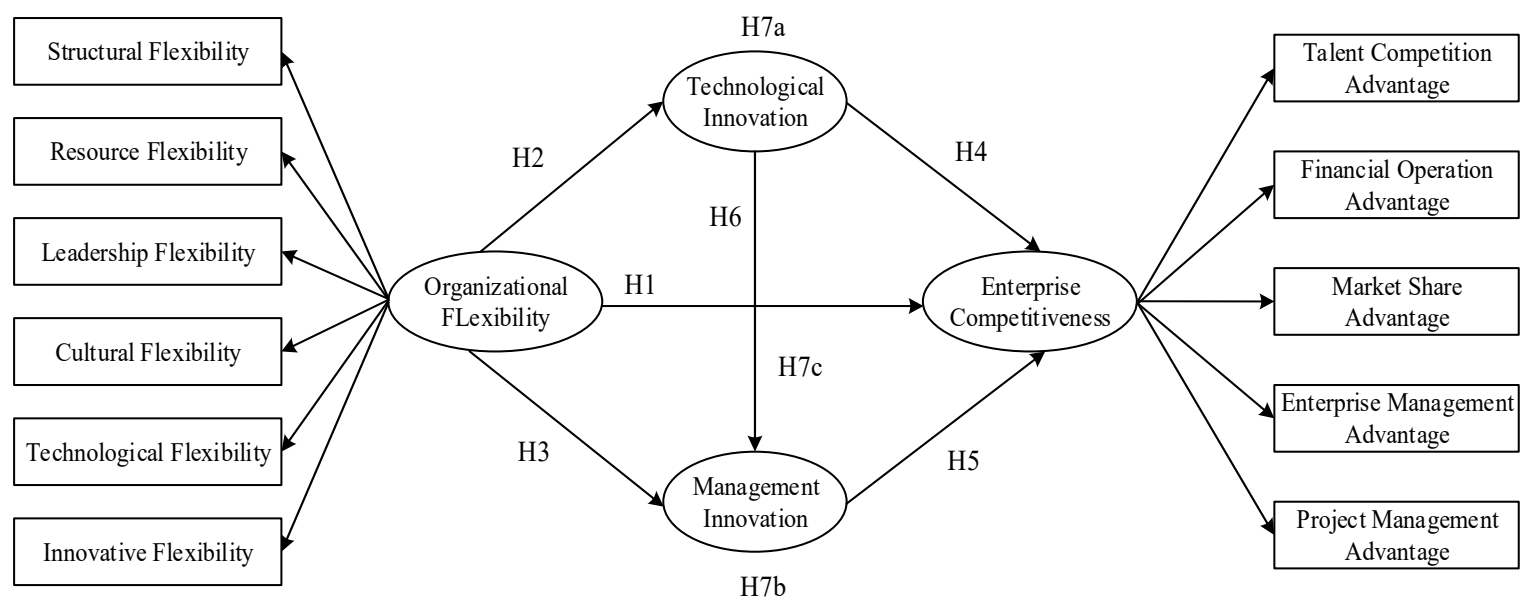

Figure 1. Theoretical model.

\section{Methodology}

\subsection{Measures and Instruments}

The scales in this study were developed based on reviewed literature to ensure the credibility of the research tool, and the localization of scale was fully considered according to advices of experts. Measurement methodology for each factor implemented a five-item scale adopted from SF-Young-Ybarra et al. [99] and Maghool [35]; RF-Mathews [64], and Martínez-Sánchez et al. [54]; LF—Phillips and Wright [100] and Baron et al. [57]; CFPhillips and Wright [100]; TF-Ozer [43] and Maghool [35]; IF-Vickery et al. [53] and Zhu and Cheung [15]; TI-Daft [24] and Ozorhon et al. [76]; MI-Hamel [101], Crossan and Apaydin [82] and Zhu and Cheung [15]; EC(TCA/FOA/MSA/EMA/PMA)—Shen et al. [102], Tan et al. [103], Lu et al. [30], Orozco et al. [77], and Zhu and Cheung [15]. Based on the measurement scale mentioned above, this study developed a questionnaire with a total of 13 scales and 65 items. The items in the questionnaire are listed in Appendix A. 


\subsection{Sample and Data Collection}

The hypotheses were tested by structured questionnaire surveys. As OF and EC of PBEs are interactive, various employees in China's construction industry comprised the sample respondent pool. Survey samples mainly involve senior managers, middle managers, junior managers, and common employees from various PBEs, specifically, construction, engineering management, real estate development, design, engineering consulting, and other firms in China's construction industry.

The questionnaire was originally done in English. The authors used a back-translation approach [104], which translated the original tool into Chinese according to the Chinese context. After modification and confirmation by two independent professors, the validity of the measurement project was tested. Then, the authors conducted an initial pilot test by selecting some employees in the construction industry through random selection in order to check whether respondents could accurately understand the wording and meaning of the questions. The survey questions were revised according to the pilot questionnaire analysis data. Finally, after the preliminary questionnaire was revised, the final Chinese questionnaire was developed for data collection. The Likert-type scale was used for the questionnaire, which ranged from 1 (strongly disagree) to 5 (strongly agree). The survey lasted from January to May 2019, during which 1000 questionnaires were distributed in 29 provinces and cities, including Beijing, Shanghai, Shandong, Chongqing, and Jiangsu. Among the 1000 questionnaires issued, 644 were responded to (a response rate of $64.4 \%$ ). After eliminating invalid questionnaires, 463 were found to have been answered effectively (an effective rate of $71.9 \%$ ). The demographic information of the interviewees is shown in Table 1.

Table 1. Demographic information of respondents $(\mathrm{N}=463)$.

\begin{tabular}{|c|c|c|c|}
\hline Variable & Category & Number of Cases & Frequency $(\%)$ \\
\hline \multirow{2}{*}{ Gender } & Male & 343 & 74.1 \\
\hline & Female & 120 & 25.9 \\
\hline \multirow{5}{*}{ Age } & $\leq 25$ & 108 & 23.3 \\
\hline & $26-30$ & 137 & 29.6 \\
\hline & $31-35$ & 92 & 19.9 \\
\hline & $36-40$ & 63 & 13.6 \\
\hline & $>40$ & 63 & 13.6 \\
\hline \multirow{5}{*}{ Education } & PhD & 13 & 2.8 \\
\hline & Postgraduate & 155 & 33.5 \\
\hline & Bachelor's degree & 255 & 55.1 \\
\hline & Junior college student & 34 & 7.3 \\
\hline & $\begin{array}{c}\text { Technical secondary school or } \\
\text { below }\end{array}$ & 6 & 1.3 \\
\hline \multirow{3}{*}{$\begin{array}{c}\text { Years of } \\
\text { experience }\end{array}$} & $\leq 5$ year & 294 & 63.5 \\
\hline & 5-10years & 62 & 13.4 \\
\hline & $>10$ years & 107 & 23.1 \\
\hline \multirow{5}{*}{ Position } & Senior manager & 22 & 4.8 \\
\hline & Middle manager & 92 & 19.9 \\
\hline & Junior manager & 188 & 40.6 \\
\hline & Common employees & 146 & 31.5 \\
\hline & Others & 15 & 3.2 \\
\hline \multirow{6}{*}{ Firm type } & Construction firms & 169 & 36.5 \\
\hline & Engineering management firms & 45 & 9.7 \\
\hline & Real estate development firms & 107 & 23.1 \\
\hline & Design firms & 60 & 13.0 \\
\hline & Engineering consulting firms & 23 & 5.0 \\
\hline & Other firms & 59 & 12.7 \\
\hline
\end{tabular}




\subsection{Data Analysis Methods}

Data analysis adopted Confirmatory Factor Analysis (CFA) and Structural Equation Modeling (SEM), using the SPSS 25.0 and AMOS 21.0 software. In statistics, CFA is the most commonly used special form of factor analysis in social research. The purpose of CFA test is to confirm that the data collected by the study conform to a hypothetical measurement model [105]. In this study, CFA was implemented to test the convergence and discriminant validity of the measured structural model. SEM provides support for these hypotheses and can perform path analysis.

\section{Research Results}

\subsection{CFA}

CFA modeling is used to verify the effectiveness of the overall measurement model. Both convergent and discriminant validity are considered in the study. The indicators for testing the convergent validity include factor loading, which should exceed 0.6 and be significant at the level of 0.01 , and Composite Reliability (CR), which should be greater than 0.8. Average Variance Extracted (AVE) of all constructs should be larger than 0.5 [106]. In addition, Cronbach's Alpha coefficient was used to evaluate construct reliability in this study, which should be greater than 0.70 [105]. According to CFA, factor loading of SF1 and SF2 are lower than 0.6 , so these two items are excluded from SF scale.

Table 2 presented the final results for the remining constructs, including Cronbach's alpha coefficients, factor loading, CR, and AVE. It can be seen that factor loading was always greater than 0.6 at the 0.001 significant level. The Cronbach's alpha coefficients, CR, and AVE of all items exceeded $0.7,0.8$, and 0.5 respectively. To conclude, the results show that the measurement model fully meets the reliability standard and convergent validity.

Table 2. Construct Validity and Reliability.

\begin{tabular}{|c|c|c|c|c|c|}
\hline Construct & Item & Cronbach's Alpha & Factor Loading & CR & AVE \\
\hline \multirow{3}{*}{ SF } & SF3 & & 0.736 & \multirow{3}{*}{0.825} & \multirow{3}{*}{0.611} \\
\hline & SF4 & 0.822 & 0.826 & & \\
\hline & SF5 & & 0.780 & & \\
\hline \multirow{5}{*}{$\mathrm{RF}$} & RF1 & \multirow{5}{*}{0.910} & 0.795 & \multirow{5}{*}{0.912} & \multirow{5}{*}{0.675} \\
\hline & RF2 & & 0.846 & & \\
\hline & RF3 & & 0.836 & & \\
\hline & RF4 & & 0.847 & & \\
\hline & RF5 & & 0.780 & & \\
\hline \multirow{5}{*}{$\mathrm{LF}$} & LF1 & \multirow{5}{*}{0.907} & 0.766 & \multirow{5}{*}{0.898} & \multirow{5}{*}{0.637} \\
\hline & LF2 & & 0.770 & & \\
\hline & LF3 & & 0.854 & & \\
\hline & LF4 & & 0.820 & & \\
\hline & LF5 & & 0.778 & & \\
\hline \multirow{5}{*}{$\mathrm{CF}$} & CF1 & \multirow{5}{*}{0.911} & 0.792 & \multirow{5}{*}{0.914} & \multirow{5}{*}{0.680} \\
\hline & CF2 & & 0.859 & & \\
\hline & CF3 & & 0.864 & & \\
\hline & CF4 & & 0.829 & & \\
\hline & CF5 & & 0.777 & & \\
\hline \multirow{5}{*}{ TF } & TF1 & \multirow{5}{*}{0.922} & 0.776 & \multirow{5}{*}{0.923} & \multirow{5}{*}{0.707} \\
\hline & TF2 & & 0.855 & & \\
\hline & TF3 & & 0.893 & & \\
\hline & TF4 & & 0.844 & & \\
\hline & TF5 & & 0.833 & & \\
\hline
\end{tabular}


Table 2. Cont.

\begin{tabular}{|c|c|c|c|c|c|}
\hline Construct & Item & Cronbach's Alpha & Factor Loading & CR & AVE \\
\hline \multirow{5}{*}{ IF } & IF1 & \multirow{5}{*}{0.916} & 0.816 & \multirow{5}{*}{0.914} & \multirow{5}{*}{0.680} \\
\hline & IF2 & & 0.872 & & \\
\hline & IF3 & & 0.867 & & \\
\hline & IF4 & & 0.804 & & \\
\hline & IF5 & & 0.760 & & \\
\hline \multirow{5}{*}{ TI } & TI1 & \multirow{5}{*}{0.936} & 0.830 & \multirow{5}{*}{0.931} & \multirow{5}{*}{0.731} \\
\hline & TI2 & & 0.804 & & \\
\hline & TI3 & & 0.882 & & \\
\hline & TI4 & & 0.863 & & \\
\hline & TI5 & & 0.894 & & \\
\hline \multirow{5}{*}{ MI } & MI1 & \multirow{5}{*}{0.948} & 0.814 & \multirow{5}{*}{0.947} & \multirow{5}{*}{0.781} \\
\hline & MI2 & & 0.854 & & \\
\hline & MI3 & & 0.916 & & \\
\hline & MI4 & & 0.916 & & \\
\hline & MI5 & & 0.914 & & \\
\hline \multirow{5}{*}{ TCA } & TCA1 & \multirow{5}{*}{0.925} & 0.808 & \multirow{5}{*}{0.926} & \multirow{5}{*}{0.715} \\
\hline & TCA2 & & 0.855 & & \\
\hline & TCA3 & & 0.846 & & \\
\hline & TCA4 & & 0.867 & & \\
\hline & TCA5 & & 0.849 & & \\
\hline \multirow{5}{*}{ FOA } & FOA1 & \multirow{5}{*}{0.924} & 0.855 & \multirow{5}{*}{0.925} & \multirow{5}{*}{0.711} \\
\hline & FOA2 & & 0.858 & & \\
\hline & FOA3 & & 0.829 & & \\
\hline & FOA4 & & 0.801 & & \\
\hline & FOA5 & & 0.871 & & \\
\hline \multirow{5}{*}{ MSA } & MSA1 & \multirow{5}{*}{0.919} & 0.857 & \multirow{5}{*}{0.920} & \multirow{5}{*}{0.697} \\
\hline & MSA2 & & 0.835 & & \\
\hline & MSA3 & & 0.844 & & \\
\hline & MSA4 & & 0.837 & & \\
\hline & MSA5 & & 0.800 & & \\
\hline \multirow{5}{*}{ EMA } & EMA1 & \multirow{5}{*}{0.944} & 0.859 & & \\
\hline & EMA2 & & 0.894 & & \\
\hline & EMA3 & & 0.884 & 0.945 & 0.774 \\
\hline & EMA4 & & 0.912 & & \\
\hline & EMA5 & & 0.848 & & \\
\hline & PMA1 & & 0.844 & & \\
\hline & PMA2 & & 0.891 & & \\
\hline PMA & PMA3 & 0.941 & 0.879 & 0.941 & 0.761 \\
\hline & PMA4 & & 0.868 & & \\
\hline & PMA5 & & 0.878 & & \\
\hline
\end{tabular}

Note: SF = Structural Flexibility; RF = Resource Flexibility; LF = Leadership Flexibility; CF = Cultural Flexibility; $\mathrm{TF}=$ Technological Flexibility; IF = Innovative Flexibility; TI = Technological Innovation; MI = Management Innovation; TCA = Talent Competition Advantage; FOA = Financial Operation Advantage; MSA = Market Share Advantage; EMA = Enterprise Management Advantage; PMA = Project Management Advantage.

Two criteria for evaluating discriminant validity were identified [106,107]. This study adopted the one proposed by [107], which suggested that the AVE of each latent variable is greater than the correlation coefficients between the same construct and any other construct. Table 3 presents the results of the descriptive statistics and correlation analysis. It can be inferred that the measurement model achieves appropriate discriminant validity as the diagonal elements are found to exceed respective off-diagonal elements. Besides, all correlation coefficients reveal significant positive correlations between all variables. Furthermore, this study assessed the collinearity between all measure variables by adopting the collinearity diagnostics. The results show that the maximal Variance Inflation Factor 
(VIF) value is 5.587, well below the recommended cut-off of 10 [108], which indicates that there is no evident multicollinearity problem between measure variables.

Table 3. Descriptive Statistics and Correlation Analysis $(\mathrm{N}=463)$.

\begin{tabular}{|c|c|c|c|c|c|c|c|c|c|c|c|c|c|c|c|}
\hline Variable & Mean & SD & SF & RF & LF & $\mathrm{CF}$ & TF & IF & TI & MI & TCA & FOA & MSA & EMA & PMA \\
\hline SF & 3.846 & 0.733 & 0.782 & & & & & & & & & & & & \\
\hline RF & 3.715 & 0.764 & $0.668 * *$ & 0.822 & & & & & & & & & & & \\
\hline LF & 3.767 & 0.740 & $0.739 * *$ & $0.768^{* *}$ & 0.798 & & & & & & & & & & \\
\hline $\mathrm{CF}$ & 3.854 & 0.732 & $0.738^{* *}$ & $0.666^{* *}$ & $0.845^{* *}$ & 0.825 & & & & & & & & & \\
\hline $\mathrm{TF}$ & 3.747 & 0.740 & $0.633^{* *}$ & $0.824^{* *}$ & $0.798^{* *}$ & $0.713^{* *}$ & 0.841 & & & & & & & & \\
\hline $\mathrm{IF}$ & 3.691 & 0.752 & $0.666^{* *}$ & $0.722 * *$ & $0.748^{* *}$ & $0.734^{* *}$ & $0.824^{* *}$ & 0.825 & & & & & & & \\
\hline TI & 3.588 & 0.784 & 0.572 ** & 0.741 ** & $0.699 * *$ & $0.629 * *$ & $0.791^{* *}$ & $0.791^{* *}$ & 0.855 & & & & & & \\
\hline MI & 3.625 & 0.773 & $0.609 * *$ & $0.708^{* *}$ & 0.702 ** & 0.623 ** & $0.739 * *$ & 0.757 ** & $0.818^{* *}$ & 0.884 & & & & & \\
\hline TCA & 3.646 & 0.758 & 0.625 ** & 0.650 ** & $0.713^{* *}$ & $0.686^{* *}$ & $0.719^{* *}$ & $0.754^{* *}$ & $0.722 * *$ & $0.744^{* *}$ & 0.846 & & & & \\
\hline FOA & 3.651 & 0.778 & $0.554^{* *}$ & $0.555^{* *}$ & 0.623 ** & $0.614^{* *}$ & $0.633^{* *}$ & $0.625^{* *}$ & 0.585 ** & $0.597 * *$ & $0.742^{* *}$ & 0.843 & & & \\
\hline MSA & 3.682 & 0.722 & $0.593^{* *}$ & $0.644^{* *}$ & $0.684 * *$ & $0.638^{* *}$ & $0.711^{* *}$ & 0.681 ** & $0.713^{* *}$ & $0.699 * *$ & 0.740 ** & $0.785^{* *}$ & 0.835 & & \\
\hline EMA & 3.638 & 0.760 & $0.615^{* *}$ & $0.593 * *$ & $0.678^{* *}$ & $0.653 * *$ & $0.666^{* *}$ & $0.695^{* *}$ & $0.666^{* *}$ & 0.682 ** & $0.752^{* *}$ & $0.759 * *$ & $0.805^{* *}$ & 0.880 & \\
\hline PMA & 3.695 & 0.724 & $0.616^{* *}$ & $0.603^{* *}$ & $0.685^{* *}$ & $0.675^{* *}$ & $0.677^{* *}$ & $0.690^{* *}$ & $0.652^{* *}$ & $0.658^{* *}$ & $0.757^{* *}$ & 0.742 ** & $0.785^{* *}$ & $0.869^{* *}$ & 0.872 \\
\hline
\end{tabular}

Note: $\mathrm{SD}=$ Standard Deviations. The diagonal italic values are the square roots of AVE. ${ }^{* *}=$ Equals significant at the 0.01 level (two-tailed).

Adopting Hair et al.'s [109] approach, the measurement model fit is evaluated using indicators/parameters as follows:

- Absolute fit measures: Chi-square degree of freedom ratio ( $\left.\chi^{2} / \mathrm{df}\right)$, Root Mean Square (RMS), Residual (RMR), Goodness-Of-Fit index (GFI), and RMS Error of Approximation (RMSEA);

- Incremental fit measures: Incremental Fit Index (IFI), Tucker-Lewis Index (TLI), and Adjusted Goodness-Of-Fit index (AGFI) and Comparative Fit Index (CFI);

- Parsimonious fit measures: Parsimony Goodness-Of-Fit index (PGFI), and Parsimony Comparative Fit Index (PCFI).

According to the data in Table 4, the fit indexes of the measurement models all reach the standard $[44,105]$, which means the measurement model fit the survey data well. Therefore, the measurement models proposed in this paper are completely applicable to test the research hypothesis.

Table 4. Overall Fit Indices of the Scales.

\begin{tabular}{|c|c|c|c|c|c|c|c|c|c|c|c|}
\hline \multicolumn{2}{|c|}{ Fit Index } & $x^{2} / \mathrm{df}$ & RMR & RMSEA & GFI & AGFI & TLI & IFI & CFI & PGFI & PCFI \\
\hline \multirow{3}{*}{ scale } & OF & 3.193 & 0.033 & 0.069 & 0.848 & 0.815 & 0.929 & 0.938 & 0.938 & 0.694 & 0.824 \\
\hline & OI & 2.764 & 0.017 & 0.062 & 0.964 & 0.936 & 0.983 & 0.989 & 0.989 & 0.543 & 0.681 \\
\hline & EC & 2.562 & 0.019 & 0.058 & 0.894 & 0.870 & 0.960 & 0.965 & 0.965 & 0.729 & 0.852 \\
\hline \multicolumn{2}{|c|}{$\begin{array}{l}\text { Recommended } \\
\text { cutoff value }\end{array}$} & $\begin{array}{l}\leq 3^{a} \\
\leq 5^{b}\end{array}$ & $\leq 0.05$ & $\begin{array}{l}<0.08^{a} \\
<0.1^{b}\end{array}$ & $\begin{array}{l}\geq 0.9^{a} \\
\geq 0.8^{b}\end{array}$ & $\begin{array}{l}\geq 0.9^{\mathrm{a}} ; \\
\geq 0.8^{\mathrm{b}}\end{array}$ & $\geq 0.9$ & $\geq 0.9$ & $\geq 0.9$ & $\geq 0.5$ & $\geq 0.5$ \\
\hline \multicolumn{2}{|c|}{ Fit? } & YES & YES & YES & YES & YES & YES & YES & YES & YES & YES \\
\hline
\end{tabular}

Note: OF = Organizational Flexibility; OI = Organizational Innovation; EC = Enterprise Competitiveness; $\mathrm{a}=$ Equals acceptable; $\mathrm{b}=$ Equals marginal.

\subsection{SEM Analysis and Hypotheses Testing}

SEM analysis (again using AMOS 21.0) was performed to verify the hypotheses. The critical ratio and the $p$ value are two significant indicators for testing the hypothesis. Critical ratio should be higher than 1.96 [44]. The results of hypotheses testing are presented in Table 5 and Figure 2. Except for H4, all the critical ratio values exceed 1.96. OF has significant effect on EC, TI, and MI $(\beta=0.633, p<0.001 ; \beta=0.868, p<0.001 ; \beta=0.351$, $p<0.001$ ), which support $\mathrm{H} 1, \mathrm{H} 2$, and $\mathrm{H} 3$, respectively. However, influence of TI on EC is not significant $(\beta=0.041, p>0.05)$; therefore, $\mathrm{H} 4$ is rejected. MI has a significant impact on EC ( $\beta=0.234, p<0.001)$; therefore, H5 is supported. H6 is also supported as the relationship of TI on $\mathrm{MI}$ is also found to be significant $(\beta=0.556, p<0.001)$. In conclusion, except for $\mathrm{H} 4$, all direct effect hypotheses proposed in this paper have been confirmed. 
Table 5. Hypothesis Testing Results.

\begin{tabular}{cccccc}
\hline Hypothesis & Path & Path Coefficient $\boldsymbol{\beta}$ & Critical Ratio & $\boldsymbol{p}$ & Remarks \\
\hline H1 & OF-EC & 0.633 & 7.872 & $* * *$ & Supported \\
H2 & OF-TI & 0.868 & 14.137 & $* * *$ & Supported \\
H3 & OF-MI & 0.351 & 5.338 & $* * *$ & Supported \\
H4 & TI-EC & 0.041 & 0.540 & 0.589 & Rejected \\
H5 & MI-EC & 0.234 & 3.584 & $* * *$ & Supported \\
H6 & TI-MI & 0.556 & 8.503 & $* * *$ & Supported \\
\hline Note: $^{* * *}=$ Equals significant at the 0.001 level (two tailed). & & &
\end{tabular}

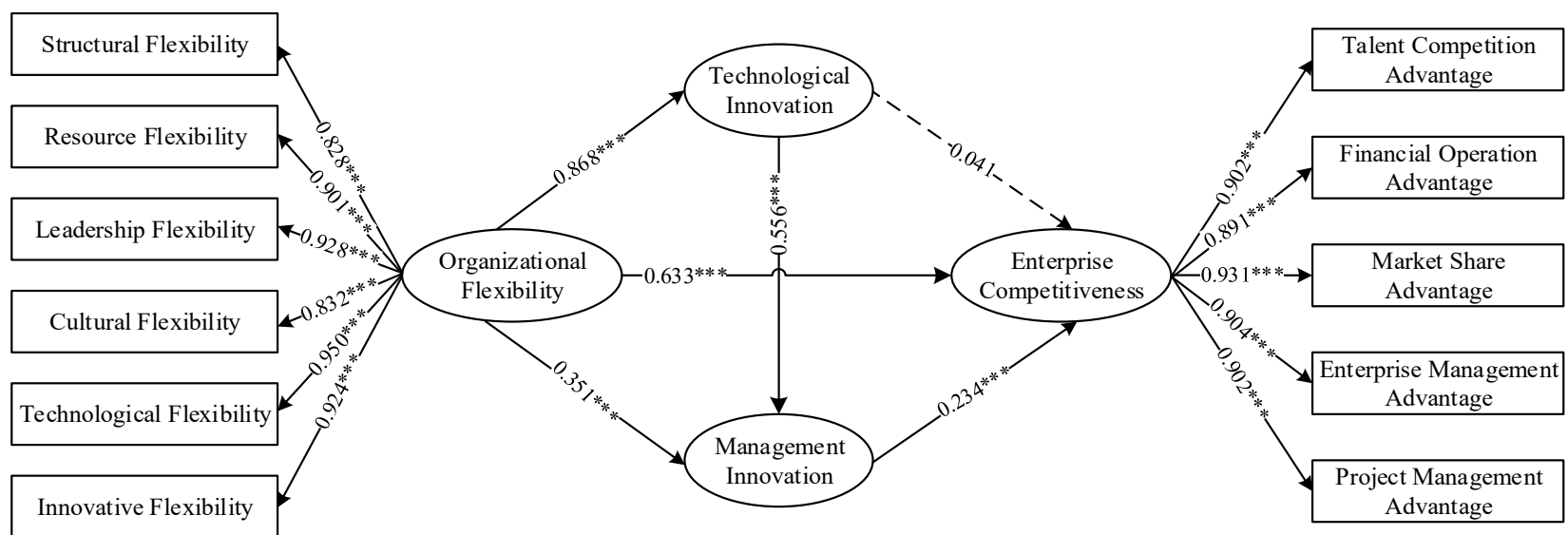

Note: $* * *=\mathrm{p}<0.001$.

Figure 2. Research model and results of hypotheses test.

\subsection{Bootstrapping}

The indirect effect was tested using bootstrapping analysis with a sample of 5000 . When the 95\% confidence interval (CI) does not include zero, it means that the indirect mediation effect is significant at a $5 \%$ level [110]. In this study, three specific mediation effects are tested. First, the CI for the effect on the pathway from OF via TI to EC included zero $(95 \% \mathrm{CI}=[-0.099,0.172])$. The result indicates that the indirect mediation effect of TI is not significant at a level of $5 \%$, thus rejecting Hypothesis 7a. Second, MI significantly mediates the effect of OF and EC, with $95 \%$ CI [0.030, 0.144]. Thus, Hypothesis $7 \mathrm{~b}$ is supported. Third, the CI for the effect on the pathway from OF via TI and MI to EC excluded zero $(95 \% \mathrm{CI}=[0.047,0.198])$. It means the serial mediation effect of TI and MI between OF and EC is significant at a level of 5\%, thus supporting Hypothesis 7c.

\section{Discussion}

\subsection{Summary of Findings}

This study is aimed at exploring the mechanism for EC promotion of PBEs in Chinese construction industry against the background of $\mathrm{MCI}$ with a specific focus on $\mathrm{OF}$ and $\mathrm{OI}$ when OI is considered including TI and MI. Five major findings are presented as follows after carrying out empirical analysis.

- $\quad$ OF has a significant and positive effect on EC with the influence effect of 0.633.

- OF is positively related with TI and MI, with the influence effect of 0.868 and 0.351 , respectively.

- The influence effect of MI on EC is 0.234 , while the direct influence between TI and EC is not supported.

- TI has a direct influence on MI with the influence effect of 0.556 . 
- MI significantly mediates the relation between OF and EC. The indirect mediation effect of TI is not significant. TI and MI play a serial mediation role in the relationship between OF and EC.

The results show that OF is an effective predictor of EC, which is in line with previous evidence [7]. Organizations with flexibility can react to environmental changes and uncertainties (e.g., velocity of technological advancement, increased competition, market fluctuations [6]) more quickly by absorbing change, integrating, and developing and restructuring resources and capabilities in a short time [8], which is beneficial to successfully navigating crisis situations and gaining advantages in the fierce market competition [41]. The uncertainty of an environment could be an opportunity or challenge depending on whether an organization can adjust according to new market demands effectively. In generally, firms with higher flexibility tend to exist and prosper [7].

Besides, the findings of this study show that OF is conducive to promoting TI and MI. OF generates creativity [53], allowing the firm to develop new products or services and make adjustments in management regulation, process, and method to adapt to market demands quickly [9]. Furthermore, previous studies demonstrated that the dimensions of organizational flexibility that are established in this paper (SF/RF/LF/CF/TF/IF) can positively promote OI. For example, effective leadership encourages creativity and foster ingenuity in individual project teams across the construction sector [15,77]. External human resource flexibility is also positively related with innovation [54].

Moreover, MI is found to have a direct influence on EC, which is aligned with a previous study [74]. The indirect effect testing results indicate that MI serves as a significant mediating function in the relationship between OF and EC. As analyzed in this study, firms with flexibility in some aspects (e.g., leadership [57], culture [95]) are more likely to respond to environmental changes actively by making adjustments in management practices to satisfy market acquirements and gain competitive advantages.

The empirical results show that TI has no direct positive influence on EC, which is the opposite to the conclusion drawn by Li et al. (2019) [91], and that the indirect mediation effect of TI is not significant. Interestingly, the indirect mediation effect of MI between OF and EC is significant, both in the serial mediation of TI and MI. The authors attempt to make the following explanations. In theory, TI in other literatures may be defined in an overly broad fashion, involving innovation in management, which is not consistent with this study. Moreover, the concept of competitiveness proposed in this paper is aimed at PBEs in the construction industry (see Section 2.1), which is not the same as existing definition [31]. It is universally acknowledged that the industry background and market development trend need to be considered fully when establishing competitiveness assessment indicators [29]. Therefore, the direct contribution of TI on EC may be limited to a certain industry or a special situation, which is not an eternal truth. Besides, it has been found that the influence of technological innovation output on the competitiveness of enterprises has a threshold effect and lag. Only when the number of patent applications of enterprise reaches a certain level can the innovation output promote enterprise competitiveness effectively [111]. As a practical matter, in a complex business environment, TI is a double-edged sword. On the one hand, it provides opportunities for firms to profit from innovation and improve their capabilities. On the other hand, innovation may change traditional supply chains, destroy some immature business processes, and bring expected losses to enterprises [112]. Furthermore, cycle of TI has been greatly shortened currently, and the technology penetration rate is increasing [113]. In the context of MCI, the competition in technology is intensified, and the possibility of maintaining the growth and competitiveness of enterprises through technical means is decreasing. Innovation in non-technical fields (management, etc.) is gradually considered a new breakthrough to enhance firm performance $[75,114]$. In addition, the application of new technologies poses a higher challenge to the management ability of enterprises. The introduction of innovative technologies is a common tool to promote the development of firms. However, the effectiveness of this work mainly depends on the absorption ability of 
technology receivers. The application of technology needs the support of the management practices within the organization. In other words, maximizing the value of TI requires the support of MI. Therefore, TI can effectively promote MI to some extent, which is also partly supported by research of Zhang et al. [98]. In a word, the above analysis supports the results of hypotheses $\mathrm{H} 6$ and $\mathrm{H7c}$, that is, TI can promote MI, and TI and MI play an important serial mediation between $\mathrm{EC}$ and OF.

\subsection{Theoretical Implications}

Existing literature presented effective research of EC promotion and obtained significant research outcomes in the construction industry. Although researchers in the construction industry agree on the importance of gaining OF in a constantly changing business environment $[6,7,47,49,50]$, specific effects of OF on EC require additional consideration and testing. The mediating role of OI, including TI and MI, also needs further study. This paper presents the first attempt to establish the theoretical connection between $\mathrm{OF}, \mathrm{OI}$, and EC in the construction industry in a single research framework. This study clarifies the direct influence effect of OF on EC, while verifying important mediating role of MI and serial mediating functions of TI and MI between them. These are the outstanding theoretical contribution to PBEs based on the context of MCI in China. However, the mediating role of TI between OF and EC is not significant, which is an interesting result. The author has given some explanations in theory and practice, which is helpful to re-examine the role of TI in enhancing EC.

In addition, previous research explored multiple types of flexibility from different perspectives and their importance. Key elements include product development [52], supply chain [53], process [47,55], operational [115,116], strategic [117], leadership [56,57], project team [58], financial, structural, technological [35], cross-cultural [59], contractual [60], and human resource flexibilities [54]. However, existing literature exploring construction industry PBEs OF is scarce. According to existing research, OF measurement structures are not uniform. Applying MCI to Chinese construction industry, OF measurement structure is grouped into six dimensions: SF, RF, LF, CF, TF, and IF. New and beneficial attempts in the construction industry have been well verified and contribute to literature on $\mathrm{OF}$ theory, especially dimensions of CF and IF proposed by this paper in particular. Similarly, considering the difference between PBEs and other types of organizations, this manuscript establishes the measurement structure about EC from five competitive perspectives: TCA, FOA, MSA, EMA, and PMA. All of them return good reliability and validity results and can pass the empirical test. Therefore, the proposed measurement scales (of OF and EC) can provide a reference for scholars to perform similar research.

\subsection{Practical Implications}

In the process of MCI in China, PBEs construction leaders and managers should consider implementing EC in order to survive and prosper in turbulent market environments. Based on empirical evidence, the findings of this study provide guidelines for PBEs' senior management, as well as practitioners, to make policies and strategies for gaining sustainable development and competitiveness. Researching and discussing EC improvement mechanisms from the comprehensive perspective of OF and OI can inspire the construction industry in China. Faced with the uncertainty in the context of MCI, OF provides an effective solution. By strengthening OF in terms of structure, resources, leadership, culture, technology, and innovation the environmental adaptability of firms can be significantly enhanced, which is conducive to seizing opportunities or avoiding underlying risks through dynamic learning so as to gain competitiveness. In addition, the serial mediating function of TI and MI in improving EC has been tested. Thus, OI should be valued by embracing TI as a power source, which further contributes in promoting MI. Coupling these components amplifies the benefits within the organization. Therefore, it is recommend that PBEs emphasize TI and MI to improve sustainability and performance, rather than focusing only on TI. 


\subsection{Limitations and Future Research}

First of all, this paper adopted the questionnaire survey to test the theoretical model of China's construction industry with cross-sectional data. The data merely reflect the relationship, as well as regular rules, in the short term with a Chinese context. Future research is needed to conduct research in a long termed and longitudinal perspective. The research results should be examined via repeated research subjects, so as to verify the validity of the results. Although the results of this study could be an important and valued reference for Chinese construction PBEs leaders and managers who want to keep enterprise competitive advantage when responding to uncertainties and challenges brought by $\mathrm{MCI}$. However, how to apply the theoretical results better to practice for enterprises is also a problem to be explored and solved.

Furthermore, this paper studied the common influence laws of OF and OI on EC in PBEs because the number of research samples in this study is insufficient to distinguish different types of PBEs for comparative analysis. However, it can be speculated that different types of enterprises may require different types of organizational flexibility. Therefore, if possible, more data can be collected for a specific focus on one type of enterprise (e.g., construction, design, engineering management, etc.).

Finally, this paper exclusively investigated the influence mechanism of OF and OI on EC in PBEs, but offers an interesting topic to analyze and study the factors affecting OF for PBEs. The results show that OF has a significant positive effect on EC, which provides a reference for improving EC from the perspective of flexibility. However, this paper only defines the connotation and develops the measurement dimension of $\mathrm{OF}$, but the formation mechanism of $\mathrm{OF}$ and related influencing factors are not covered in this paper. Therefore, the authors suggest that more attention should be paid to these two aspects and how to improve the PBEs' OF should be further analyzed. In addition, the optimal level of the OF for an enterprise is also an important and interesting issue that need to be explored.

\section{Conclusions}

The MCI strategy influences improvement and development of China's construction industry, causing numerous uncertainties and complex external environment changes for various PBEs. Improving the enterprise competitiveness constantly and surviving and developing in fierce market competition are the focus of the leaders and managers of PBEs in China at present. Therefore, greater attention should be paid to improving PBEs' enterprise competitiveness. This paper explored improvement mechanism of enterprise competitiveness, focusing on organizational flexibility and organizational innovation. The following conclusions are drawn:

(1) Organizational flexibility can positively affect enterprise competitiveness significantly in China's construction industry. This indicates the need to improve PBEs' organizational flexibility so organizations can cope with the challenges and opportunities generated by MCI.

(2) Technological innovation and management innovation can play an important serial mediating role between organizational flexibility and enterprise competitiveness in the construction industry, and strengthening technological innovation and management innovation improves the enterprise competitiveness of PBEs. Furthermore, technological innovation positively facilitates management innovation, and resultant development strategy, organizational structure, management system, management process, and management method innovations should be compatible with technological innovation in PBEs.

(3) The measurement structure of organizational flexibility including structural flexibility, resource flexibility, leadership flexibility, cultural flexibility, technological flexibility, and innovative flexibility has been well verified, and measurement scales offer proven reliability and validity. Strengthening the structural flexibility, resource flexibility, leadership flexibility, cultural flexibility, technological flexibility, and innovative flexibility of the organization enhances organizational flexibility capabilities. 
(4) The measurement structure of enterprise competitiveness involving talent competition advantage, financial operation advantage, market share advantage, enterprise management advantage, and project management advantage has also been well tested, and measurement scales were found to have ideal reliability and validity. Therefore, through strengthening the advantages associated with talent competition, financial operation, market share, enterprise management, and project management enterprise competitiveness of PBEs can be reinforced further.

Author Contributions: Conceptualization, G.N.; methodology, G.N. and H.X.; software, H.X.; validation, G.N., Z.Z. and H.L.; formal analysis, G.N. and Q.C.; investigation, G.N., Z.Z. and H.L.; resources, G.N.; data curation, Y.Q. and H.X.; writing-original draft preparation, G.N., H.X., Z.Z. and H.L.; writing-review and editing, Q.C., Y.Q. and P.J.H.; supervision, G.N. and Q.C.; project administration, G.N.; funding acquisition, G.N. All authors have read and agreed to the published version of the manuscript.

Funding: This research was funded by the National Natural Science Foundation of China, grant number 72071201 and the Fundamental Research Funds for the Central Universities in China, grant number 2020ZDPYMS30.

Institutional Review Board Statement: Not applicable.

Informed Consent Statement: Not applicable.

Data Availability Statement: The data presented in this study are available on request from the corresponding author.

Conflicts of Interest: The authors declare no conflict of interest.

\section{Appendix A}

Table A1. Questionnaire items in measurement scales.

\begin{tabular}{|c|c|c|}
\hline Construct & Code & Measurement Item \\
\hline \multirow{5}{*}{ SF } & SF1 & Your firm carries out organizational structure reform in response to the MCI. \\
\hline & SF2 & Your firm is able to actively prepare or perfect specialized organizations to cope with the MCI. \\
\hline & SF3 & Your firm advocates inter-departmental cooperation and communication within the organization. \\
\hline & SF4 & Your firm can fully arise the initiative of functional departments in response to MCI. \\
\hline & SF5 & Your firm establishes strategic cooperation with other firms to adapt to the MCI. \\
\hline \multirow{5}{*}{ RF } & RF1 & Leaders and employees in your firm are good at learning and applying relevant knowledge of the MCI. \\
\hline & RF2 & Your firm attaches great importance to the training and education of employees related to the MCI. \\
\hline & RF3 & Your firm can be equipped with all kinds of equipment required for the MCI timely. \\
\hline & RF4 & Your firm is good at capturing and utilizing information related to the MCI. \\
\hline & RF5 & Your firm can raise funds to meet the needs of the MCI timely. \\
\hline \multirow{5}{*}{ LF } & LF1 & Leaders of your firm pay close attention to the relevant policies and development status of the MCI. \\
\hline & LF2 & Leaders of your firm often adopt advices on facilitating the MCI. \\
\hline & LF3 & Leaders of your firm are good at motivating employees and display their subjective initiative. \\
\hline & LF4 & Leaders of your firm can respect, trust, understand and care for employees. \\
\hline & LF5 & Leaders of your firm can treat the success and failure of his subordinates objectively and fairly. \\
\hline \multirow{5}{*}{$\mathrm{CF}$} & CF1 & Your firm is open and willing to develop the MCI. \\
\hline & CF2 & Your firm encourages free communication between superiors and subordinates. \\
\hline & CF3 & Your firm advocates teamwork and win-win cooperation. \\
\hline & CF4 & Your firm encourages employees to learn and communicate across functional areas. \\
\hline & CF5 & Your firm attaches great importance to humanistic care for employees. \\
\hline \multirow{5}{*}{$\mathrm{TF}$} & TF1 & Your firm attaches great importance to the impact of technological revolution on economic benefits. \\
\hline & TF2 & Your firm is good at introducing relevant technologies to develop the MCI. \\
\hline & TF3 & Your firm can apply the relevant technologies of the MCI timely. \\
\hline & TF4 & Your firm is good at predicting the development trend of technology in the construction industry. \\
\hline & TF5 & Your firm values investment in technology research and development. \\
\hline
\end{tabular}


Table A1. Cont.

\begin{tabular}{|c|c|c|}
\hline Construct & Code & Measurement Item \\
\hline \multirow{5}{*}{ IF } & IF1 & Your firm attaches great importance to the recruitment and introduction of innovative talents. \\
\hline & IF2 & Your firm pays attention to the cultivation of employees' innovative consciousness and ability. \\
\hline & IF3 & Your firm advocates continuous innovation in the reform of the construction industry. \\
\hline & IF4 & Your firm can provide financial support for employees to do innovative work. \\
\hline & IF5 & Your firm focuses on rewarding employees for their innovations. \\
\hline \multirow{5}{*}{ TI } & TI1 & Your firm has implemented technological innovation related to the $\mathrm{MCI}$, independently or cooperatively. \\
\hline & TI2 & Your firm has obtained a number of patents or unique technologies related to the MCI. \\
\hline & TI3 & Your firm has improved traditional construction or management techniques in response to the MCI. \\
\hline & TI4 & Your firm has adapted traditional production or management tools in response to the MCI. \\
\hline & TI5 & Your firm can launch new products or services to cope with the market changes timely. \\
\hline \multirow{5}{*}{ MI } & MI1 & Your firm has adjusted development strategy in response to the MCI. \\
\hline & MI2 & Your firm has innovated organizational structure in response to the MCI. \\
\hline & MI3 & Your firm has innovated management regulation in response to the MCI. \\
\hline & MI4 & Your firm has innovated management procedure in response to the MCI. \\
\hline & MI5 & Your firm has innovated management methods in response to the MCI. \\
\hline \multirow{5}{*}{ TCA } & TCA1 & Your firm has more talents to meet the needs of MCI. \\
\hline & TCA2 & Employees have higher comprehensive quality in your firm. \\
\hline & TCA3 & Employees have strong learning ability in your firm. \\
\hline & TCA4 & Your firm has a reserve of talents \\
\hline & TCA5 & Your firm receives more attention or favor from job seekers. \\
\hline \multirow{5}{*}{ FOA } & FOA1 & You firm has more solid financial support. \\
\hline & FOA2 & You firm has stronger financing capacity. \\
\hline & FOA3 & Your firm is in good financial condition. \\
\hline & FOA4 & You firm has higher cost control ability. \\
\hline & FOA5 & Your firm is more capable of capital appreciation. \\
\hline \multirow{5}{*}{ MSA } & MSA1 & Your firm is able to respond to market needs or opportunities timely. \\
\hline & MSA2 & Business scope is more suitable for the $\mathrm{MCI}$ in your firm. \\
\hline & MSA3 & Your firm has a higher winning rate in the market. \\
\hline & MSA4 & Your firm has better marketing and public relations ability. \\
\hline & MSA5 & Your firm has a better corporate reputation and image. \\
\hline \multirow{5}{*}{ EMA } & EMA1 & Modern enterprise system is more sound in your firm. \\
\hline & EMA2 & Internal processes are more efficient in your firm. \\
\hline & EMA3 & Internal communication mechanism is better in your firm. \\
\hline & EMA4 & Functional departments and project teams in your firm can cooperate effectively. \\
\hline & EMA5 & There are closer relationships between your firm and partners. \\
\hline \multirow{5}{*}{ PMA } & PMA1 & Your firm gives project team more powers and responsibilities. \\
\hline & PMA2 & Project team has a stronger comprehensive strength in your firm. \\
\hline & PMA3 & Project team' cohesion is stronger in your firm. \\
\hline & PMA4 & Operation mechanism of project team is more reasonable in your firm. \\
\hline & PMA5 & Project team can provide a higher quality product or service in your firm. \\
\hline
\end{tabular}

\section{References}

1. Drobyazko, S.; Barwińska-Małajowicz, A.; Ślusarczyk, B.; Zavidna, L.; Danylovych-Kropyvnytska, M. Innovative entrepreneurship models in the management system of enterprise competitiveness. J. Entrep. Educ. 2019, 22, 1-6.

2. Orozco, F.A.; Serpell, A.F.; Molenaar, K.R.; Forcael, E. Modeling competitiveness factors and indexes for construction companies: Findings of Chile. J. Constr. Eng. Manag. 2014, 140, B4013002. [CrossRef]

3. Tan, Y.; Xue, B.; Cheung, Y.T. Relationships between main contractors and subcontractors and their impacts on main contractor competitiveness: An empirical study in Hong Kong. J. Constr. Eng. Manag. 2017, 143, 05017007. [CrossRef]

4. Stoyanova, T.; Angelova, M. Impact of the internal factors on the competitiveness of business organizations. In Proceedings of the 2018 International Conference on High Technology for Sustainable Development (HiTech) IEEE, Sofia, Bulgaria, 11-14 June 2018; pp. 1-3.

5. Dubey, R.; Gunasekaran, A.; Childe, S.J.; Fosso Wamba, S.; Roubaud, D.; Foropon, C. Empirical investigation of data analytics capability and organizational flexibility as complements to supply chain resilience. Int. J. Prod. Res. 2019, 1-19. [CrossRef] 
6. Lim, B.T.; Ling, F.Y.; Ibbs, C.W.; Raphael, B.; Ofori, G. Mathematical models for predicting organizational flexibility of construction firms in Singapore. J. Constr. Eng. Manag. 2012, 138, 361-375. [CrossRef]

7. Lim, B.T.; Ling, F.Y.; Ibbs, C.W.; Raphael, B.; Ofori, G. Empirical analysis of the determinants of organizational flexibility in the construction business. J. Constr. Eng. Manag. 2011, 137, 225-237. [CrossRef]

8. Gonçalves, J.M.; Ferreira, F.A.F.; Ferreira, J.J.M.; Farinha, L.M.C. A multiple criteria group decision-making approach for the assessment of small and medium-sized enterprise competitiveness. Manag. Decis. 2019, 57, 480-500. [CrossRef]

9. Saeed, M.A.; Jiao, Y.; Zahid, M.M.; Tabassum, H.; Nauman, S. Organizational flexibility and project portfolio performance: The roles of innovation, absorptive capacity and environmental dynamism. Int. J. Manag. Proj. Bus. 2020. [CrossRef]

10. Liu, J.; Li, B.; Lin, B.; Nguyen, V. Key issues and challenges of risk management and insurance in China's construction industry: An empirical study. Ind. Manag. Data Syst. 2007, 107, 382-396. [CrossRef]

11. Gann, D.M.; Salter, A.J. Innovation in project-based, service-enhanced firms: The construction of complex products and systems. Res. Policy. 2000, 29, 955-972. [CrossRef]

12. Javernick-Will, A. Local embeddedness and knowledge management strategies for project-based multi-national firms. Eng. Manag. J. 2013, 25, 16-26. [CrossRef]

13. Luo, M.; Fan, H.; Liu, G. Measuring regional differences of construction productive efficiency in China: A distance friction minimization approach. Eng. Constr. Archit. Manag. 2019, 27, 952-974. [CrossRef]

14. Deng, F.; Liu, G.; Jin, Z. Factors Formulating the Competitiveness of the Chinese Construction Industry: Empirical Investigation. J. Manag. Eng. 2013, 29, 435-445. [CrossRef]

15. Zhu, L.; Cheung, S.O. Harvesting competitiveness through building organizational innovation capacity. J. Manag. Eng. 2017, 33. [CrossRef]

16. Gruneberg, S. Construction markets in a changing world economy. In Economics for the Modern Built Environment; Taylor \& Francis Group: Oxfordshire, UK, 2008; pp. 153-167.

17. Cartlidge, D. Procurement of Built Assets; Butterworth Heinemann: Oxford, UK, 2004.

18. Luo, T.; Xue, X.; Wang, Y.; Xue, W.; Tan, Y. A systematic overview of prefabricated construction policies in China. J. Clean Prod. 2020, 280. [CrossRef]

19. Huang, J. Research on information industry innovation model under the background of integration of industrialization and informatization. In Proceedings of the 7th International Conference on Innovation \& Management, Wuhan, China, 4-5 December 2010; pp. 588-592.

20. Zhai, X.; Reed, R.; Mills, A. Addressing sustainable challenges in China: The contribution of off-site industrialization. Smart Sustain. Built Environ. 2014, 3, 261-274. [CrossRef]

21. Cao, D.; Li, H.; Wang, G.; Luo, X.; Tan, D. Relationship network structure and organizational competitiveness: Evidence from BIM implementation practices in the construction industry. J. Manag. Eng. 2018, 34, 04018005. [CrossRef]

22. Dess, G.G.; Picken, J.C. Changing roles: Leadership in the 21st century. Organ. Dyn. 2000, 28, 18-34. [CrossRef]

23. Ungerman, O.; Dedkova, J.; Gurinova, K. The impact of marketing innovation on the competitiveness of enterprises in the context of industry 4.0. J. Compet. 2018, 10, 132-148. [CrossRef]

24. Daft, R.L. A dual-core model of organizational innovation. Acad. Manag. J. 1978, 21, 193-210.

25. Evan, W.M. Organizational lag. Hum. Organ. 1966, 25, 51-53. [CrossRef]

26. Dereli, D.D. Innovation management in global competition and competitive advantage. Procedia Soc. Behav. Sci. 2015, 195, 1365-1370. [CrossRef]

27. Ajitabh, A.; Momaya, K. Competitiveness of firms: Review of theory, frameworks and models. Singap. Manag. Rev. 2004, 26, 45-61.

28. Falciola, J.; Jansen, M.; Rollo, V. Defining firm competitiveness: A multidimensional framework. World Dev. 2020, 129 , 104857. [CrossRef]

29. Afanasieva, N.V.; Rodionov, D.G.; Vasilev, Y.N. System of indicators of coal enterprise competitiveness assessment. Espacios 2018, $39,10$.

30. Lu, W.; Shen, L.; Yam, M.C. Critical success factors for competitiveness of contractors: China study. J. Constr. Eng. Manag. 2008, 134, 972-982. [CrossRef]

31. Yamova, O.; Maramygin, M.; Sharova, I.; Nesterenko, J.; Sobina, N. Integral valuation of an enterprise's competitiveness in the industrial economy. Eur. Res. Stud. 2018, 21, 777-786.

32. Ghobadian, A.; Viney, H.; Liu, J.; James, P. Extending linear approaches to mapping corporate environmental behaviour. Bus. Strategy Environ. 1998, 7, 13-23. [CrossRef]

33. Xu, T.; Tiong, R.L.; Chew, D.A.; Smith, N.J. Development model for competitive construction industry in the People's Republic of China. J. Constr. Eng. Manag. 2005, 131, 844-853. [CrossRef]

34. Dikmen, I.; Birgonul, M.T.; Kiziltas, S. Prediction of organizational effectiveness in construction companies. J. Constr. Eng. Manag. 2005, 131, 252-261. [CrossRef]

35. Maghool, A. Investigating the effect of flexibility (operational, financial, structural and technological) required for Banking Industry on the correlation between the strategic planning and the organization efficiency. Am. J. Sci. 2013, 9, 102-109.

36. Abdelilah, B.; El Korchi, A.; Balambo, M.A. Flexibility and agility: Evolution and relationship. J. Manuf. Technol. Mana. 2018, 29, 1138-1162. [CrossRef] 
37. Prater, E.; Biehl, M.; Smith, M.A. International supply chain agility-Tradeoffs between flexibility and uncertainty. Int. J. Oper. Prod. Man. 2001, 21, 823-839. [CrossRef]

38. Backhouse, C.J.; Burns, N.D. Agile value chains for manufacturing-implications for performance measures. Int. J. Agil. Manag. Systems 1999, 1, 76-82. [CrossRef]

39. Koev, S.R.; Pavliuk, S.; Derhaliuk, M.; Sokolova, L.; Portna, O. Resource Strategy for Enterprise Management as a Tool to Ensure Its Competitiveness. Acad. Strateg. Manag. J. 2020, 19, 1-8.

40. Lin, H.; Zeng, S.X.; Ma, H.Y.; Qi, G.Y.; Tam, V.W. Can political capital drive corporate green innovation? Lessons from China. J. Clean. Prod. 2014, 64, 63-72. [CrossRef]

41. McManus, S.; Seville, E.; Vargo, J.; Brunsdon, D. Facilitated process for improving organizational resilience. Nat. Hazards Rev. 2008, 9, 81-90. [CrossRef]

42. Úbeda-García, M.; Claver-Cortés, E.; Marco-Lajara, B.; Zaragoza-Sáez, P.; García-Lillo, F. High performance work system and performance: Opening the black box through the organizational ambidexterity and human resource flexibility. J. Bus. Res. 2018, 88, 397-406. [CrossRef]

43. Ozer, M. The role of flexibility in online business. Bus. Horiz. 2002, 45, 61-69. [CrossRef]

44. Ni, G.; Cui, Q.; Sang, L.; Wang, W.; Xia, D. Knowledge-sharing culture, project-team interaction, and knowledge-sharing performance among project members. J. Manag. Eng. 2018, 34, 04017065. [CrossRef]

45. Lansley, P.R. Corporate strategy and survival in the UK construction industry. Constr. Manag. Econ. 1987, 5, 141-155. [CrossRef]

46. Ho, S.P.; Liu, L.Y. How to evaluate and invest in emerging A/E/C technologies under uncertainty. J. Constr. Eng. Manag. 2003, 129, 16-24. [CrossRef]

47. Gil, N.; Tommelein, I.D.; Stout, A.; Garrett, T. Embodying product and process flexibility to cope with challenging project deliveries. J. Constr. Eng. Manag. 2005, 131, 439-448. [CrossRef]

48. Langford, D.A.; Male, S.P. Strategic Management in Construction, 2nd ed.; Blackwell Science: London, UK, 2001.

49. Lansley, P.R. A practical approach to auditing organizational flexibility. Constr. Manag. Econ. 2006, 1, 145-156. [CrossRef]

50. Olsson, N.O. Management of flexibility in projects. Int. J. Proj. Manag. 2006, 24, 66-74. [CrossRef]

51. Eriksson, P.E.; Larsson, J.; Pesamaa, O. Managing complex projects in the infrastructure sector-a structural equation model for flexibility-focused project management. Int. J. Proj. Manag. 2017, 35, 1512-1523. [CrossRef]

52. Thomke, S.; Reinertsen, D. Agile product development: Managing development flexibility in uncertain environments. Calif. Manag. Rev. 1998, 41, 8-30. [CrossRef]

53. Vickery, S.N.; Calantone, R.; Dröge, C. Supply chain flexibility: An empirical study. J. Supply Chain Manag. 1999, 35, 16-24. [CrossRef]

54. Martínez-Sánchez, Á.; Vela-Jimenez, M.; Abella-Garces, S.; Gorgemans, S. Flexibility and innovation: Moderator effects of cooperation and dynamism. Pers. Rev. 2019, 48, 1548-1564. [CrossRef]

55. Chou, M.C.; Teo, C.P.; Zheng, H. Process flexibility: Design, evaluation, and applications. Flex. Serv. Manuf. 2008, 20, 59-94. [CrossRef]

56. Singh, A.; Jampel, G. Leadership flexibility space. J. Manag. Eng. 2010, 26, 176-188. [CrossRef]

57. Baron, L.; Rouleau, V.; Grégoire, S.; Baron, C. Mindfulness and leadership flexibility. J. Manag. Dev. 2018, 37, 165-177. [CrossRef]

58. Zhang, L.; He, J.; Zhou, S. Sharing tacit knowledge for integrated project team flexibility: Case study of integrated project delivery. J. Constr. Eng. Manag. 2013, 139, 795-804. [CrossRef]

59. Cray, D.; McKay, R.; Mittelman, R. Cultural intelligence and mindfulness: Teaching MBAs in Iran. J. Int. Educ. Bus. 2018, 11, 220-240. [CrossRef]

60. Song, H.; Zhu, F.; Klakegg, O.J.; Wang, P. Relationship between contractual flexibility and contractor's cooperative behavior. Int. J. Manag. Proj. Bus. 2018, 11, 382-405. [CrossRef]

61. Moreno-Luzon, M.D.; Gil-Marques, M.; Valls-Pasola, J. TQM, innovation and the role of cultural change. Ind. Manag. Data Syst. 2013, 113, 1149-1168. [CrossRef]

62. Dai, Y.; Goodale, J.C.; Byun, G.; Ding, F. Strategic flexibility in new high-technology ventures. J. Manag. Stud. 2018, 55, 265-294. [CrossRef]

63. Liu, A.M.M.; Chan, I.Y.S. Understanding the interplay of organizational climate and leadership in construction innovation. J. Manag. Eng. 2017, 33, 04017021. [CrossRef]

64. Mathews, J.A. Competitive advantages of the latecomer firm: A resource-based account of industrial catch-up strategies. Asia Pac. J. Manag. 2002, 19, 467-488. [CrossRef]

65. Lund, R. Organizational and Innovative Flexibility Mechanisms and Their Impact upon Organizational Effectiveness; DRUID Working Paper 1998 (23); Aalborg University: Aalborg, Denmark, 1998.

66. Ozorhon, B. Analysis of construction innovation process at project level. J. Manag. Eng. 2013, 29, 455-463. [CrossRef]

67. Yu, M.C.; Lu, Y.J.; Li, C.; Lin, H.; Shapira, P. More is less? The curvilinear effects of political ties on corporate innovation performance. Technol. Econ. Dev. Econ. 2019, 25, 1309-1335. [CrossRef]

68. Chen, J.; Yin, X.; Li, J. Firm innovation system: Paths for enhancing corporate indigenous innovation capability. Front. Eng. Manag. 2020, 7, 404-412. [CrossRef]

69. Lin, H.; Zeng, S.; Liu, H.; Li, C. Bridging the gaps or fecklessness? A moderated mediating examination of intermediaries' effects on corporate innovation. Technovation 2020, 94, 102018. [CrossRef] 
70. Mothe, C.; Thi, T.U.N. The link between non-technological innovations and technological innovation. Eur. J. Innov. Manag. 2010, 13, 313-332. [CrossRef]

71. Birkinshaw, J.M.; Mol, M.J. How management innovation happens. MIT Sloan Manag. Rev. 2006, 47, 81-88.

72. Birkinshaw, J.; Hamel, G.; Mol, M.J. Management innovation. Acad. Manag. Rev. 2008, 33, 825-845. [CrossRef]

73. Su, S.; Baird, K. The role of leaders in generating management innovation. Int. J. Hum. Resour. Manag. 2017, 29, 2758-2779. [CrossRef]

74. Kraśnicka, T.; Głód, W.; Wronka-Pośpiech, M. Management innovation, pro-innovation organisational culture and enterprise performance: Testing the mediation effect. Rev. Manag. Sci. 2018, 12, 737-769. [CrossRef]

75. Allahar, H. A management innovation approach to project planning. Technol. Innov. Manag. Rev. 2019, 9, 4-13. [CrossRef]

76. Ozorhon, B.; Oral, K.; Demirkesen, S. Investigating the components of innovation in construction projects. J. Manag. Eng. 2016 32, 04015052. [CrossRef]

77. Ozorhon, B.; Abbott, C.; Aouad, G. Integration and leadership as enablers of innovation in construction: Case study. J. Manag. Eng. 2014, 30, 256-263. [CrossRef]

78. Liu, A.M.M.; Chan, I.Y.S. Critical role of the learning transfer climate in fostering innovation in construction. J. Manag. Eng. 2017, 33, 04016050. [CrossRef]

79. Lijauco, F.; Gajendran, T.; Brewer, G.; Rasoolimanesh, S.M. Impacts of culture on innovation propensity in small to medium enterprises in construction. J. Constr. Eng. Manag. 2020, 146, 04019116. [CrossRef]

80. Brockmann, C.; Brezinski, H.; Erbe, A. Innovation in construction megaprojects. J. Constr. Eng. Manage. 2016, $142,04016059$. [CrossRef]

81. Meng, X.; Brown, A. Innovation in construction firms of different sizes: Drivers and strategies. Eng. Constr. Archit. Manag. 2018, 25, 1210-1225. [CrossRef]

82. Crossan, M.M.; Apaydin, M. A multi-dimensional framework of organizational innovation: A systematic review of the literature. J. Manag. Stud. 2010, 47, 1154-1191. [CrossRef]

83. Oke, A. A framework for analysing manufacturing flexibility. Int. J. Oper. Prod. Manag. 2005, 25, 973-996. [CrossRef]

84. Riolli, L.; Savicki, V. Information system organizational resilience. Omega 2003, 31, 227-233. [CrossRef]

85. Chan, I.Y.S.; Liu, A.M.M.; Fellows, R. Role of leadership in fostering an innovation climate in construction firms. J. Manag. Eng. 2014, 30, 06014003. [CrossRef]

86. Pellicer, E.; Yepes, V.; Correa, C.L.; Alarcón, L.F. Model for systematic innovation in construction companies. J. Constr. Eng. Manag. 2014, 140, B4014001. [CrossRef]

87. Manley, K.; McFallan, S.; Kajewski, S. Relationship between construction firm strategies and innovation outcomes. J. Constr. Eng. Manag. 2009, 135, 764-771. [CrossRef]

88. Subramaniam, M.; Youndt, M.A. The influence of intellectual capital on the types of innovative capabilities. Acad. Manag. J. 2005, 48, 450-463. [CrossRef]

89. Zhang, Y.; Khan, U.; Lee, S.; Salik, M. The influence of management innovation and technological innovation on organization performance: A mediating role of sustainability. Sustainability 2019, 11, 495. [CrossRef]

90. Zhang, J.; Chang, Y.; Zhang, L.; Li, D. Do technological innovations promote urban green development?-A spatial econometric analysis of 105 cities in China. J. Clean. Prod. 2018, 182, 395-403. [CrossRef]

91. Li, G.; Wang, X.; Su, S.; Su, Y. How green technological innovation ability influences enterprise competitiveness. Technol. Soc. 2019, 59, 101136. [CrossRef]

92. Wen, Q.; Chen, Y.; Hong, J.; Chen, Y.; Ni, D.; Shen, Q. Spillover effect of technological innovation on $\mathrm{CO}_{2}$ emissions in China's construction industry. Build. Environ. 2020, 171, 106653. [CrossRef]

93. Damanpour, F.; Szabat, K.A.; Evan, W.M. The relationship between types of innovation and organizational performance. J. Manag. Stud. 1989, 26, 587-602. [CrossRef]

94. Du, Z. A Literature Review on Institutional Environment and Technological Innovation. Am. J. Ind. Bus. Manag. 2018, 8, 1941-1950. [CrossRef]

95. Alofan, F.; Chen, S.; Tan, H. National cultural distance, organizational culture, and adaptation of management innovations in foreign subsidiaries: A fuzzy set analysis of TQM implementation in Saudi Arabia. J. Bus. Res. 2020, 109, 184-199. [CrossRef]

96. Khosravi, P.; Newton, C.; Rezvani, A. Management innovation: A systematic review and meta-analysis of past decades of research. Eur. Manag. J. 2019, 37, 694-707. [CrossRef]

97. Camison, C.; López, A.V. An examination of the relationship between manufacturing flexibility and firm performance. Int. J. Oper. Prod. Manag. 2010, 30, 853-878. [CrossRef]

98. Zhang, Z.; Yuan, Z.; Ni, G.; Lin, H.; Lu, Y. The quality traceability system for prefabricated buildings using blockchain: An integrated framework. Front. Eng. Manag. 2020, 7, 528-546. [CrossRef]

99. Young-Ybarra, C.; Wiersema, M. Strategic flexibility in information technology alliances: The influence of transaction cost economics and social exchange theory. Organ. Sci. 1999, 10, 439-459. [CrossRef]

100. Phillips, P.A.; Wright, C. E-business's impact on organizational flexibility. J. Bus. Res. 2009, 62, 1071-1080. [CrossRef]

101. Hamel, G. The why, what, and how of management innovation. Harv. Bus. Rev. 2006, 84, 72-84. [PubMed]

102. Shen, L.Y.; Lu, W.; Shen, Q.; Li, H. A computer-aided decision support system for assessing a contractor's competitiveness. Autom. Constr. 2003, 12, 577-587. [CrossRef] 
103. Tan, Y.T.; Shen, L.Y.; Yam, M.C.; Lo, A.A. Contractor key competitiveness indicators (KCIs): A Hong Kong study. Build. Environ. 2007, 18, 17-32.

104. Yang, J. The impact of knowledge sharing on organizational learning and effectiveness. J. Knowl. Manage. 2007, 11, 83-90. [CrossRef]

105. Fang, D.; Wu, C.; Wu, H. Impact of the supervisor on worker safety behavior in construction projects. J. Manag. Eng. 2015, 31, 04015001. [CrossRef]

106. Fornell, C.; Larcker, D.F. Evaluating structural equation models with unobservable variables and measurement error. J. Mark. Res. 1981, 18, 39-50. [CrossRef]

107. Chin, W.W.; Marcolin, B.L.; Newsted, P.R. A partial least squares latent variable modeling approach for measuring interaction effects: Results from a Monte Carlo simulation study and an electronic-mail emotion adoption study. Inf. Syst. Res. 2003, 14, 189-217. [CrossRef]

108. Wei, Z.; Song, X.; Wang, D. Manufacturing flexibility, business model design, and firm performance. Int. J. Prod. Econ. 2017, 193, 87-97. [CrossRef]

109. Hair, J.F.; Anderson, R.E.; Tatham, R.L.; Black, W.C. Multivariate Data Analysis, 5th ed.; Prentice Hall: Upper SaddleRiver, NJ, USA, 1998.

110. Kim, B.J. Unstable jobs cannot cultivate good organizational citizens: The sequential mediating role of organizational trust and identification. Int. J. Environ. Res. Public Health 2019, 16, 1102. [CrossRef] [PubMed]

111. Wang, L.; Wang, S.; Tao, P. R\&D Investment, Innovation Output and Enterprise Competitiveness: A Perspective of Employee Education. J. Phys. Conf. Ser. 2020, 1616. [CrossRef]

112. Yang, Y.; Guo, L.; Zhong, Z.; Zhang, M. Selection of Technological Innovation for Service-Orientated Enterprises. Sustainability 2018, 10, 3906. [CrossRef]

113. Kim, D.G.; Choi, S.O. Impact of Construction IT Technology convergence innovation on business performance. Sustainability 2018, 10, 3972. [CrossRef]

114. Giuliani, P.; Robert, M.; Roy, F.L. Reinvention of management innovation for successful implementation. Int. J. Entrep. Small Bus. 2018, 34, 343-361. [CrossRef]

115. Calvo, R.; Domingo, R.; Sebastián, M.A. Operational flexibility quantification in a make-to-order assembly system. Int. J. Flex. Manuf. Sys. 2007, 19, 247-263. [CrossRef]

116. Fisch, J.H.; Zschoche, M. The role of operational flexibility in the expansion of international production networks. Strateg. Manage. J. 2012, 33, 1540-1556. [CrossRef]

117. Javalgi, R.; Whipple, T.W.; Ghosh, A.K.; Young, R. Market orientation, strategic flexibility, and performance: Implications for services providers. J. Serv. Mark. 2005, 19, 212-221. [CrossRef] 